See discussions, stats, and author profiles for this publication at: https://www.researchgate.net/publication/318268806

\title{
Numerical analysis of break-off test method on concrete
}

Article in Construction and Building Materials · October 2017

DOI: 10.1016/j.conbuildmat.2017.05.126

CITATIONS

8

2 authors, including:

(2. Mostafa Kazemi

University of Liège

12 PUBLICATIONS 101 CITATIONS

SEE PROFILE

Some of the authors of this publication are also working on these related projects:

Analytical study on the behavior of corrosion damaged reinforced concrete beams strengthened with FRP (Finished Project) View project
88

\section{In-situ Assessment of Recycled Aggregate Concrete (Finished Project). View project \\ .}




\title{
Numerical analysis of break-off test method on concrete
}

\author{
Rahmat Madandoust ${ }^{a}$, Mostafa Kazemi $^{a}$ \\ aapepartment of Civil Engineering, University of Guilan, P.O. Box 3756,Rasht, Iran
}

Corresponding Author: RahmatMadandoust

\section{E-mail: rmadandoust@guilan.ac.ir}

Tel: +989113314970

Fax: +981333690271

\begin{abstract}
The present study is numerically focused on the break-off (B.O.) test method as a partially destructive method for assessing the in-situ strength of concrete. In this test method, a mechanical manometer is applied to a cylindrical concrete specimen in parallel to the finished surface, and it causes fracture at the base of the B.O. test specimen. Concerning the test procedure, the B.O. test method seems to be similar to the conventional modulus of rupture test. The present study intends to analyze fracture zone stress distribution by means of finite element (FE) method using ABAQUS software. The analysis demonstrates that the approximate location of fracture zone is predictable with contours of damage that have been indicated by concrete damaged plasticity which is one of the material models available for concrete in ABAQUS. Furthermore, parametric studies have been carried out for different testing dimensions. It is noteworthy that in B.O. method, surrounding area of the base of the core specimen can influence on the results and it causes an increase in ultimate force.
\end{abstract}

Keywords: break-off test, FE analysis, modulus of rupture test, flexural strength, parametric studies

\section{Introduction}

The break-off (B.O.) test method known as a partially destructive test for measuring the in-situ concrete strength was first proposed by Johansen [1] and it was subsequently surveyed by other 
researchers [2-6]. The B.O. test consists of measuring the force required to break a cylindrical concrete specimen in parallel to finished surface. In this case, specimen operates similar to a cantilever beam with circular cross section. The test specimen is prepared in the concrete with predetermined plan by using a disposable tubular plastic sleeve which is cast into the fresh concrete and then removed at the planned time of testing (shown in Fig. 1), or with unpredicted plan by drilling the hardened concrete at the time of the B.O. test shown in Fig. 2. Currently available core dimensions are shown in Fig. 3, using $70 \mathrm{~mm}$ height $(\mathrm{H})$ and $55 \mathrm{~mm}$ diameter $(\mathrm{D})$, where $\mathrm{H} / \mathrm{D}$ is approximately equal to 1.3 .
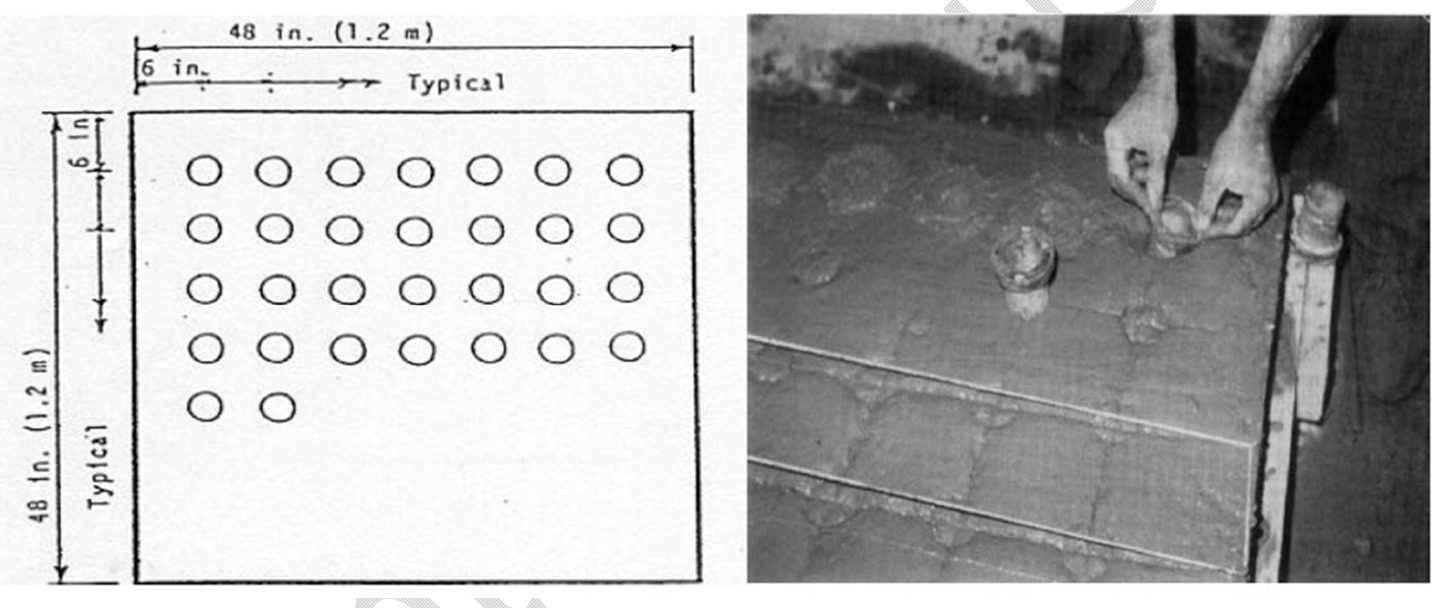

Fig.1. Inserting sleeve by rocking action and position of sleeve [2]

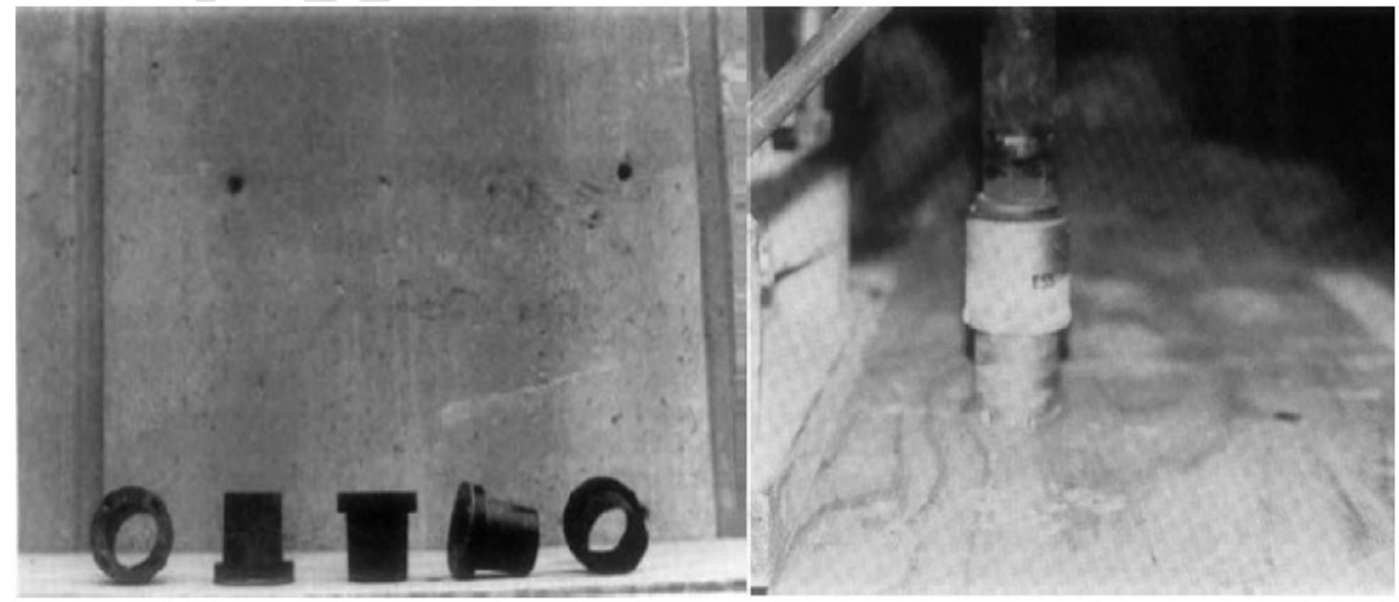

Fig.2. Tubular plastic sleeves and Core drill bit for the B.O. test [2] 


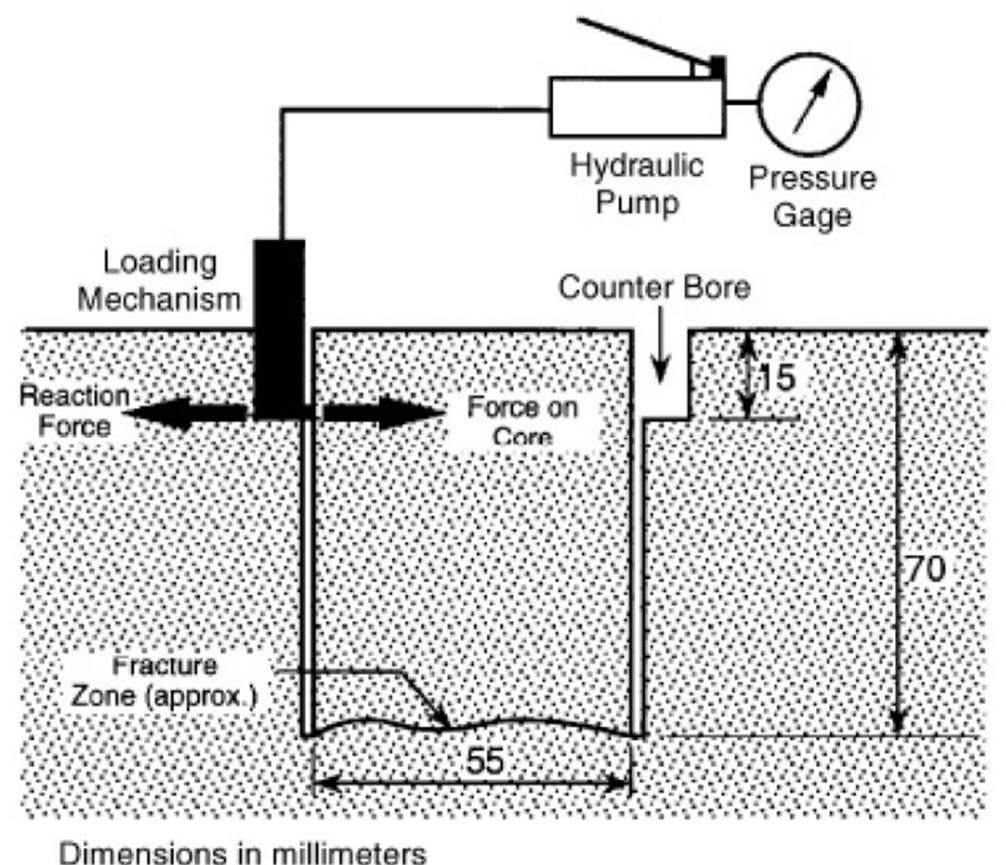

Fig.3. Fracture zone of B.O. test [10]

A number of researchers have investigated the B.O. test in experimental studies (Johansen [1]; Byfors [3]; Nishikawa [4]; Carlsson et al. [5]; Naik et al. [6]). Among the researchers, Naik et al. [6] performed the B.O. test method using inserted a plastic sleeve into the fresh concrete and drilled the hardened concrete. It has been concluded that the results for drilled hardened concrete were, on average, about 9 percent higher than the case of an inserted plastic sleeve into the fresh concrete. According to Naik et al. [6], the reason for this difference could be due to accumulation of bleeding water under the bottom edge of the sleeve which tends to create a weaker zone on concrete.

The B.O. method was standardized in England [7], Norway [8], Swedish Standard [9] and ASTM [10].As mentioned in ASTM C1150 in 2002 [11], due to limited usage of the B.O. method, it is difficult to recommend meaningful revisions to this test method, but experimental studies by Naik [2] demonstrated that the B.O. test is capable of predicting the in-situ strength of concrete and also based on ASTM C78 [12], there is a linear relationship between the B.O. flexural strength and modulus of rupture. Furthermore, recent 
study by Line et al. [13] showed that this method can evaluate the bond quality at the interface between steel bar and concrete. Their results indicated that there is a good coloration between the B.O. moment and the adhesive strength at the steel bar/concrete interface. Hence, it seems that B.O. test method could be capable to assess in-situ concrete strength and bond quality. For further investigation, this paper aims to present the results of finite element $(\mathrm{FE})$ analysis of B.O. test method studied by concrete damage plasticity model available in ABAQUS. Also parametric studies on B.O. test method are carried out on this study based on nonlinear behavior of concrete materials.

\section{Developing the material model using Concrete Damaged Plasticity}

Three crack models are available in ABAQUS software for simulating concrete elements including concrete smeared cracking, brittle cracking, and concrete damaged plasticity (CDP) [14]. Among these three models, since the CDP model is suitable for both nonlinear compressive and tensile behaviors, this technique was selected in the present study.

The CDP model is assumed to determine the tensile and compressive behavior of concrete. The compressive crushing and the tensile cracking, that are two main failure mechanisms, can be investigated using CDP model. In addition, this model can be used for monotonic and dynamic loading. Concrete behavior considered by this model is shown in Fig. 4. Eqs. (1) and (2) present the relationships between the stress and strain of concrete under tensile and compression loading, respectively.

$$
\begin{aligned}
& \sigma_{t}=\left(1-d_{t}\right) E_{0}\left(\varepsilon_{t}-\varepsilon_{t}^{p l}\right) \\
& \sigma_{c}=\left(1-d_{c}\right) E_{0}\left(\varepsilon_{c}-\varepsilon_{c}^{p l}\right)
\end{aligned}
$$


where, $E_{0}$ is the Young's modulus of concretein tension and compression, $d_{t}$ and $d_{c}$ are the damage variable in tension and compression, and $\varepsilon_{t}^{p l}$ and $\varepsilon_{c}^{p l}$ are equivalent plastic strains in tension and compression.Some properties were defined for establishing CDP model in ABAQUS are shown in Table 1. [15-18].

Table 1

Parameters used in CDP

\begin{tabular}{ccccc}
\hline Dilation angle & Eccentricity & $\mathrm{F}_{b 0} / \mathrm{F}_{c 0}$ & $\mathrm{~K}$ & $\begin{array}{c}\text { Viscosity } \\
\text { parameter }\end{array}$ \\
& & (biaxial/uniaxial ratio) & & \\
\hline $31^{\circ}$ & 0.1 & 1.16 & 0.67 & 0.0001 \\
\hline
\end{tabular}
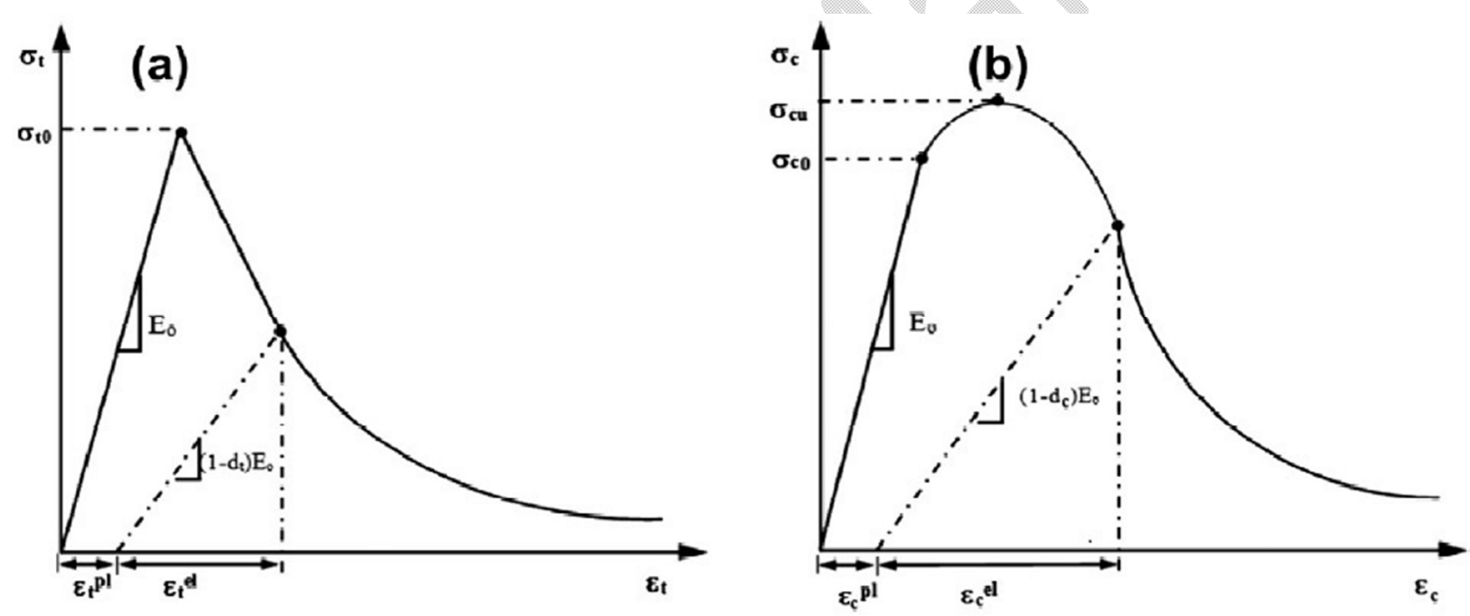

Fig.4. Concrete response under uniaxial loading in tension(a) and compression(b) [16]

The modified Hognestad stress-strain formulation [19] was used to define the concretecompressive behavior in ABAQUS (Fig. 5).In mathematical formulation of modified Hognestad model, $E_{c}$ and $f_{c}^{\prime \prime}$ is the initial modulus of elasticityandthe maximum stress in the concrete, respectively.In addition, $\varepsilon_{0}$ is the yield straincorresponding to the stress $f_{c}^{\prime \prime}$ and the ultimate compressive strain is equal to 0.0038 . 


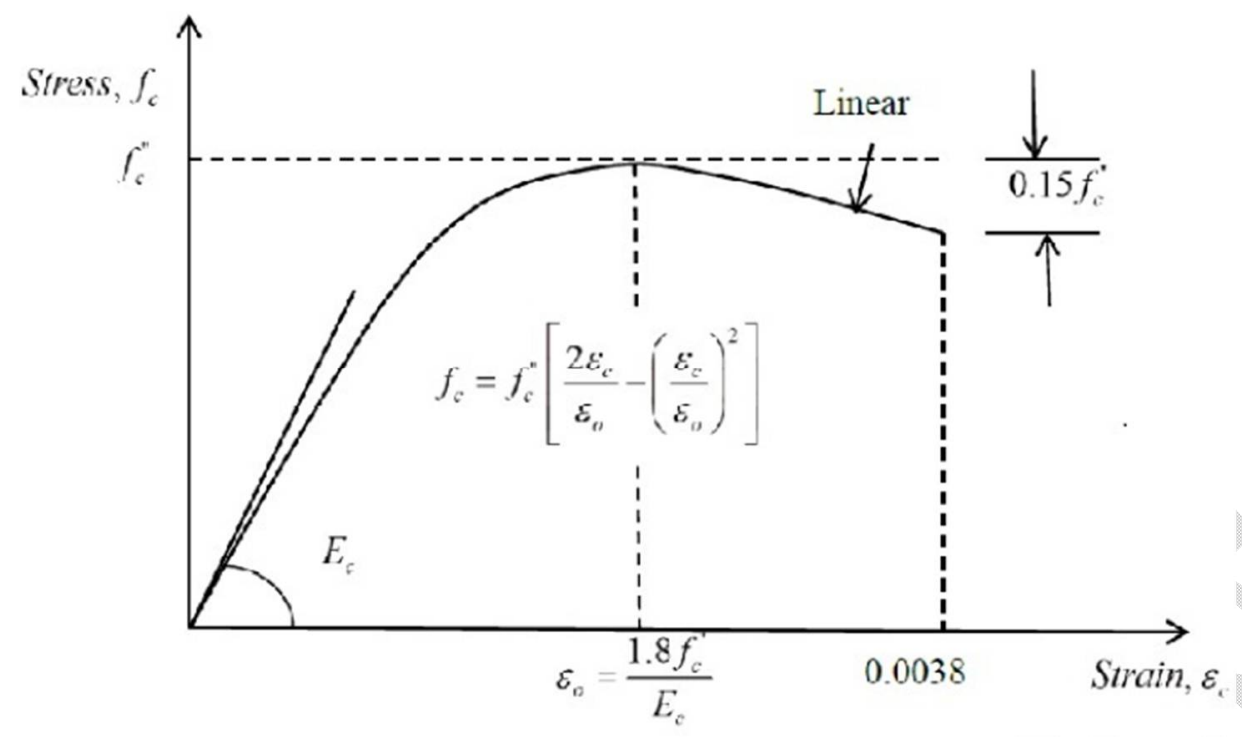

Fig.5. Modified Hognestad stress-strain model for concrete [17]

\section{Description of model properties}

The B.O. test specimen anda steel partwere generated in this model which is shown in Fig. 6.Three-dimensional (3D) hexahedral element, with 8 nodes and reduced integration (C3D8R) was used for the ABAQUS analysis. The ABAQUS tie constraint function used to connect the B.O. test specimen andsteel part. According toASTM C 1150[10], dimensionsof B.O.test specimen are $55 \mathrm{~mm}$ in diameter and $70 \mathrm{~mm}$ in height that are used in ABAQUS model.

Based on the mechanism of the test method, the B.O. force has been applied to core specimen. In numerical modeling, the B.O. force was applied to constant surface, as shown in Fig. 6. To simulate experimental conditions, boundary conditions were generated around the model to constrain the displacements and rotations in external surface that is shown in Fig. 6. 


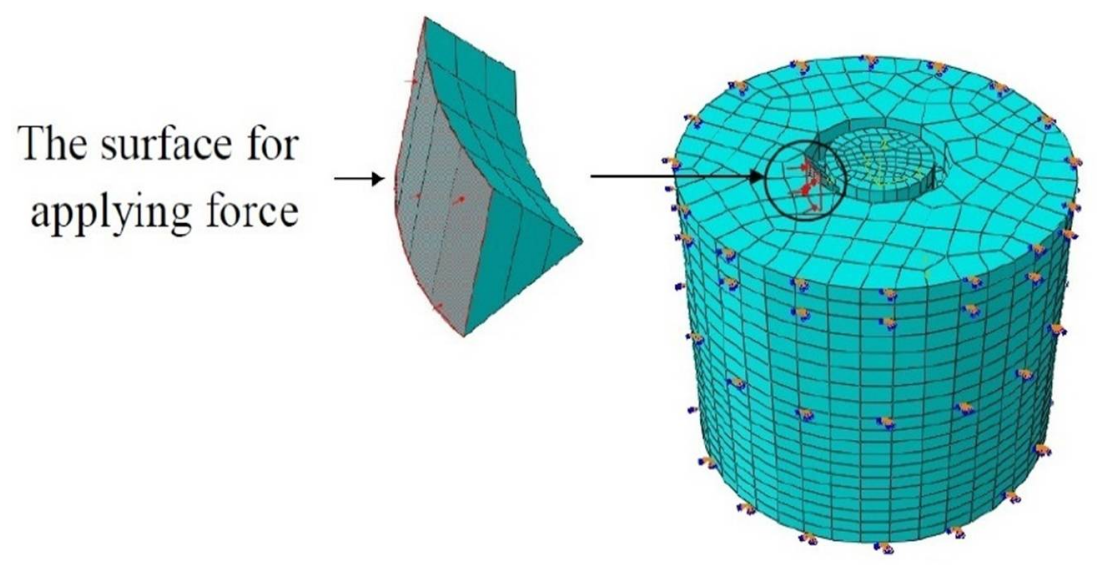

Fig. 6. The steel part and concrete specimen mesh

The values in Table 2 were used for the steel part. Also, the properties of concrete specimen used in experimental study by Niak et al. [6] are given in Table 3 .

Table 2. Properties of steel part

\begin{tabular}{ccc}
\hline Density $\left(\mathrm{kg} / \mathrm{m}^{3}\right)$ & $\begin{array}{l}\text { Modulus of } \\
\text { elasticity (MPa) }\end{array}$ & Poisson ratio \\
\hline 7830 & 200000 & 0.3 \\
\hline
\end{tabular}

Table 3. Parameters for experimental concrete used in this research [6]

\begin{tabular}{ccccccc}
\hline Mix & $\begin{array}{c}\text { Cylinder } \\
\text { Compressive } \\
\text { strength } \\
(\mathrm{MPa})\end{array}$ & $\begin{array}{l}\text { B.O. } \\
\text { readings } \\
(\mathrm{MPa})\end{array}$ & $\begin{array}{c}\text { Density } \\
\left(\mathrm{kg} / \mathrm{m}^{3}\right)\end{array}$ & $\begin{array}{c}\text { Modulu } \\
\text { s of } \\
\text { elasticity } \\
(\mathrm{MPa})\end{array}$ & $\begin{array}{c}\text { Poisson } \\
\text { ratio }\end{array}$ & $\begin{array}{c}\text { Tensile } \\
\text { strength } \\
(\mathrm{MPa})\end{array}$ \\
\hline 1 & 41.13 & 8.7 & 2448.8 & 30100 & 0.2 & 4.113 \\
\hline 2 & 43.58 & 11 & 2419.8 & 31000 & 0.2 & 4.358 \\
\hline 3 & 50.34 & 10.6 & 2403.96 & 33400 & 0.2 & 5.034 \\
\hline 4 & 56.19 & 12.4 & 2466.4 & 35200 & 0.2 & 5.619 \\
\hline
\end{tabular}

To perform the nonlinear analysis, FE software ABAQUS was employed to generate 3D FE models to numerically simulate the B.O. test. The general purpose of the analysis is to indicate distribution of maximum principal stress, predict fracture zone, and obtain the ultimate force. The generated models were validated by B.O. readings obtained by Naik et al. [6] are shown in Table 
3 , using tubular plastic sleevesinto the $12.7 \mathrm{~cm}$ (5 in) concrete slabs in a freshstate. The model was meshed with hexahedron shape. Also the geometric order for elements was considered linear in ABAQUS. The cross section used for the B.O. analysis is shown in Fig. 7.

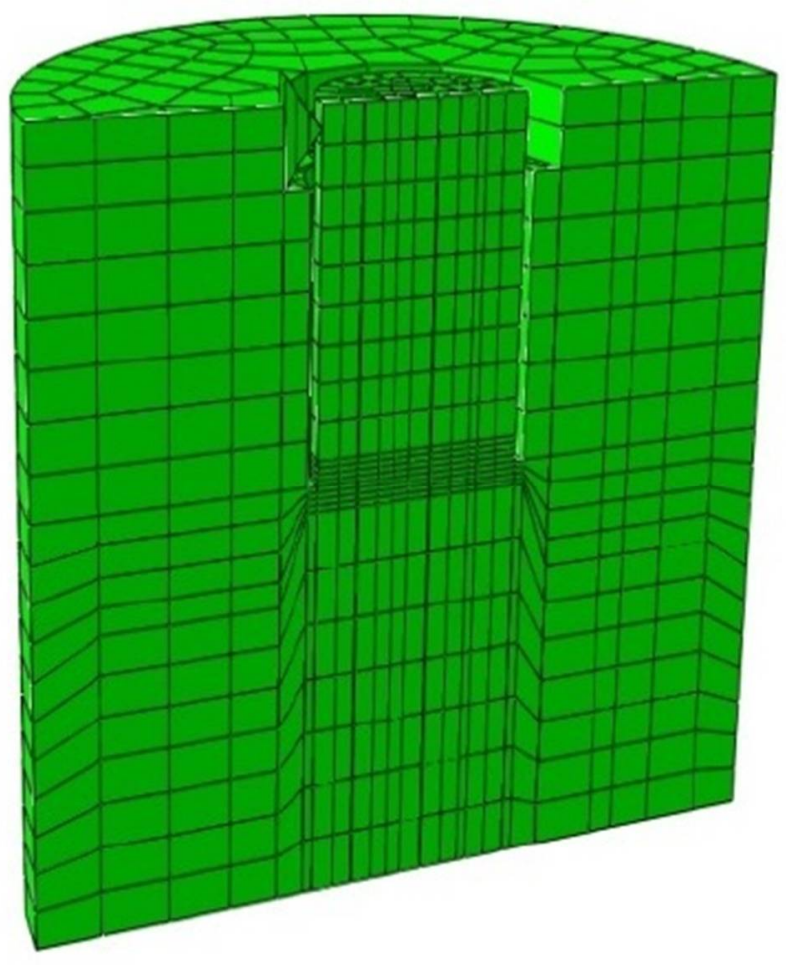

Fig. 7. Mesh configuration for the B.O. model

\section{Verification of FE model}

The purpose of presentnumerical studies was to observe the location of high stress intensities to investigate fracture zone, and not to assessdevelopment procedure of stresses in B.O. test method.Thus, the ultimate forces alone seem to be sufficient for verification. The comparison between experimental and numericalresultsincludes ultimate force - cylinder compressive strength curves and failure modes.

As shown in Fig. 8, the values of the ultimate forces obtained by numerical studies are very close to experimental results and also both curves show a steady rise trends and nearly have a similar slope. 
Another important point is that, the contours of damage in tension and compression given in Fig. 9

show that the crack propagation path approximately occurs at the base of the B.O. test specimen. This manner is also specifiedbyASTMC1150 [10] (Fig. 3).According to the presented studies, it can be said that the simulation behavior of FE of B.O.test suitably agrees with the experimental results.

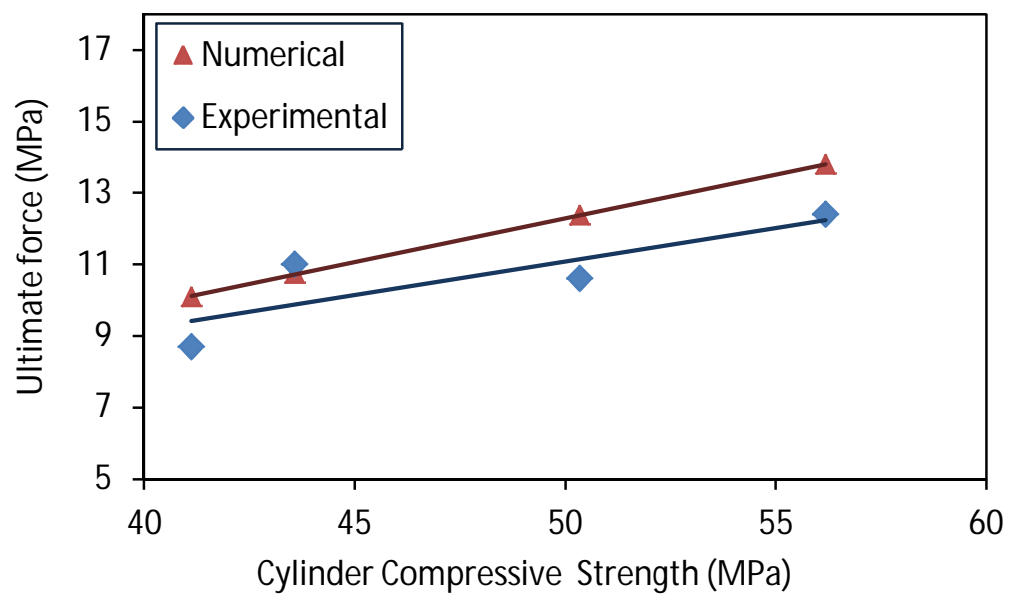

Fig. 8. Ultimate force obtained from experimental and numerical studies
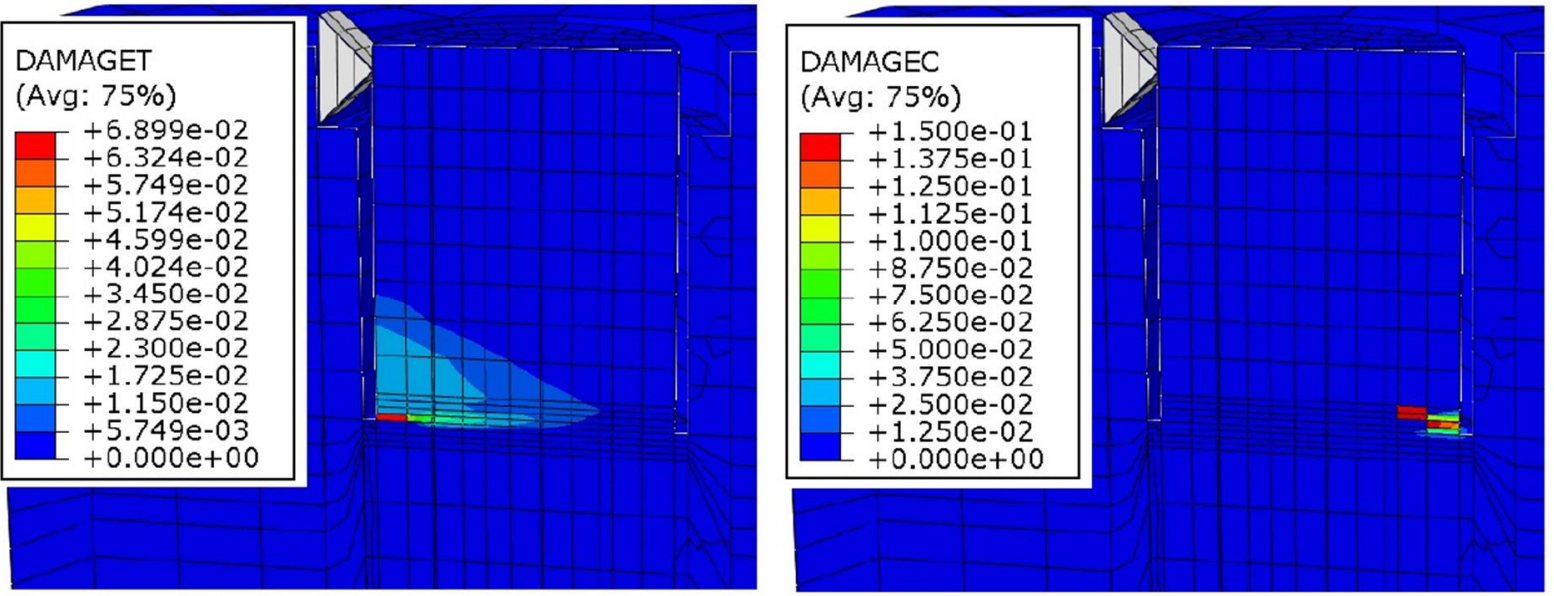

Fig. 9. Evolution of tensile and compression damage 


\section{Results and discussions on FE analysis}

The numerical model provides more understanding of distribution of the stress and the ultimate capacity of B.O. core specimens and also the failure mechanism. As mentioned previously, it is obvious that the crack propagation path can be predicted by contour of damage. According to damageevolution modes shown in Fig. 9, a crack is initiated from the bottom corner ofB.O.core specimen. Afterwardby increasing the ultimate force, fracture process is developed in parallel to finished surface.The contour plot of tensile damage variable (DAMAGET) in Fig. 9reveals that the fracture mechanism of B.O. method involves nearly tensile damage evolution modes.According to Fig. 10, it is worth noting thathigh stress intensitiesoccur in fracture zone and in the vicinity of itand the maximum stress occursat the base of the B.O. core specimenis found to be roughly 5.12MPa.

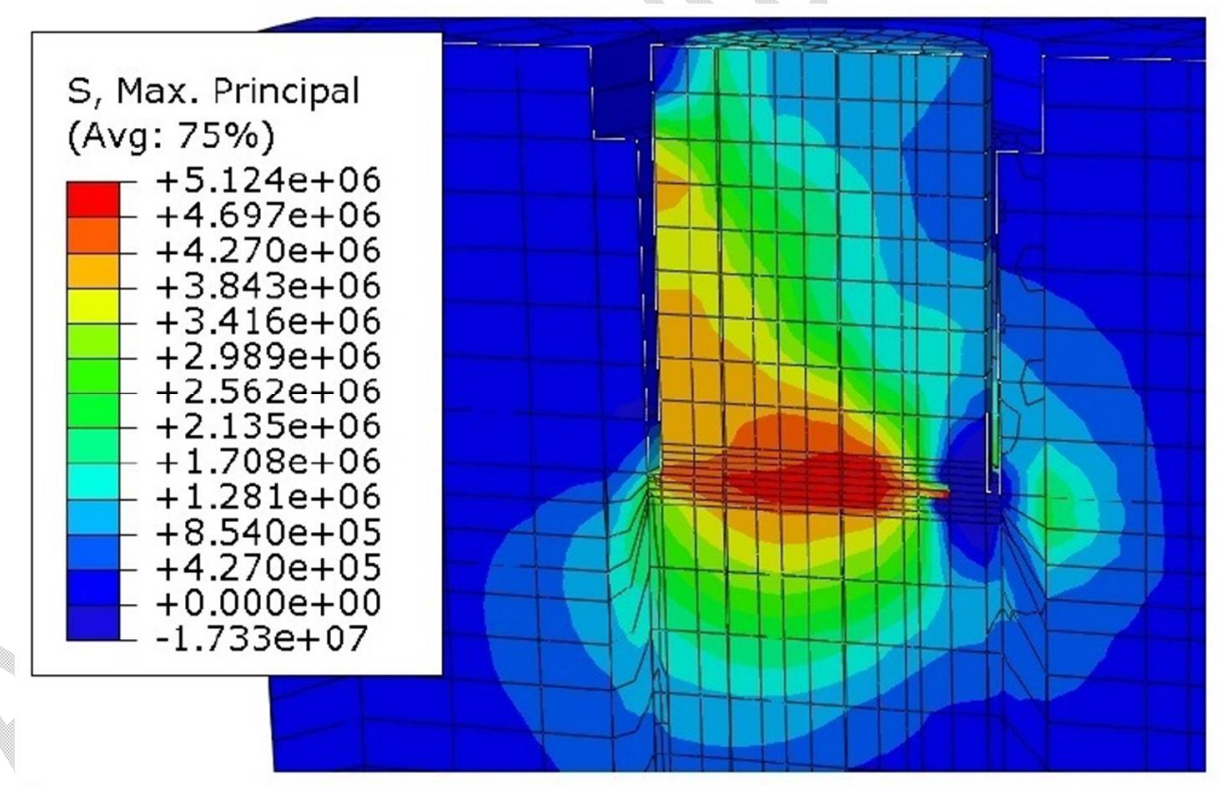

Fig.10. The distribution of maximum principal stress $(\mathrm{D}=55 \mathrm{~mm}, \mathrm{H}=70 \mathrm{~mm})$

Fig. 10 showsthe distribution of maximum principal stress, where the compressive strength of concrete is $41 \mathrm{MPa}$. The investigation of numerical results shows that, when the fracture process occurs at the base of the B.O. core specimen, some energy is absorbed in a volume of material located around 
the core specimen and this manner causes an increase in ultimate force. As shown in Fig. 8, the ultimate force of B.O. test obtained by numerical studies is, on average, about 10 percent higher than experimental results. This difference might be due to the accumulation of bleeding water under the bottom edge of the sleeve as reported by other researcher [6] which would tend to create a weaker zone of concrete exactly where the failure for the B.O. inserted sleeve test occurs. Therefore, the small difference shown in Fig. 8 is negligible.

The results obtained from the FE modelshow that the stresses are propagated under a circle of radius 60 mmwhich has been measured from the center of core specimen in Fig. 10.Consequently, the minimumcenter to center distance of $150 \mathrm{~mm}$ considered between the sleeves in experimental studiesseems to besuitable (shown in Fig. 1).

\section{Parametric Studies}

To study the effects of cylindrical core dimensions in ultimate force, diameter and height were increased in numerical studies. As shown in Fig. 11, only if the diameter is increased by $10 \mathrm{~mm}$, the ultimate force is increased by 65 percent, compared to currently available core dimensions. However, increasing in height by $15 \mathrm{~mm}$ will give reverse result and causes a decrease in ultimate force by 19 percent. However, keeping H/D ratio of 1.3 in accordance with currently available core dimensions, increasing both height and diameter of core by $15 \mathrm{~mm}$ and $10 \mathrm{~mm}$ respectively will lead to an increase in ultimate force by 34 percent. 


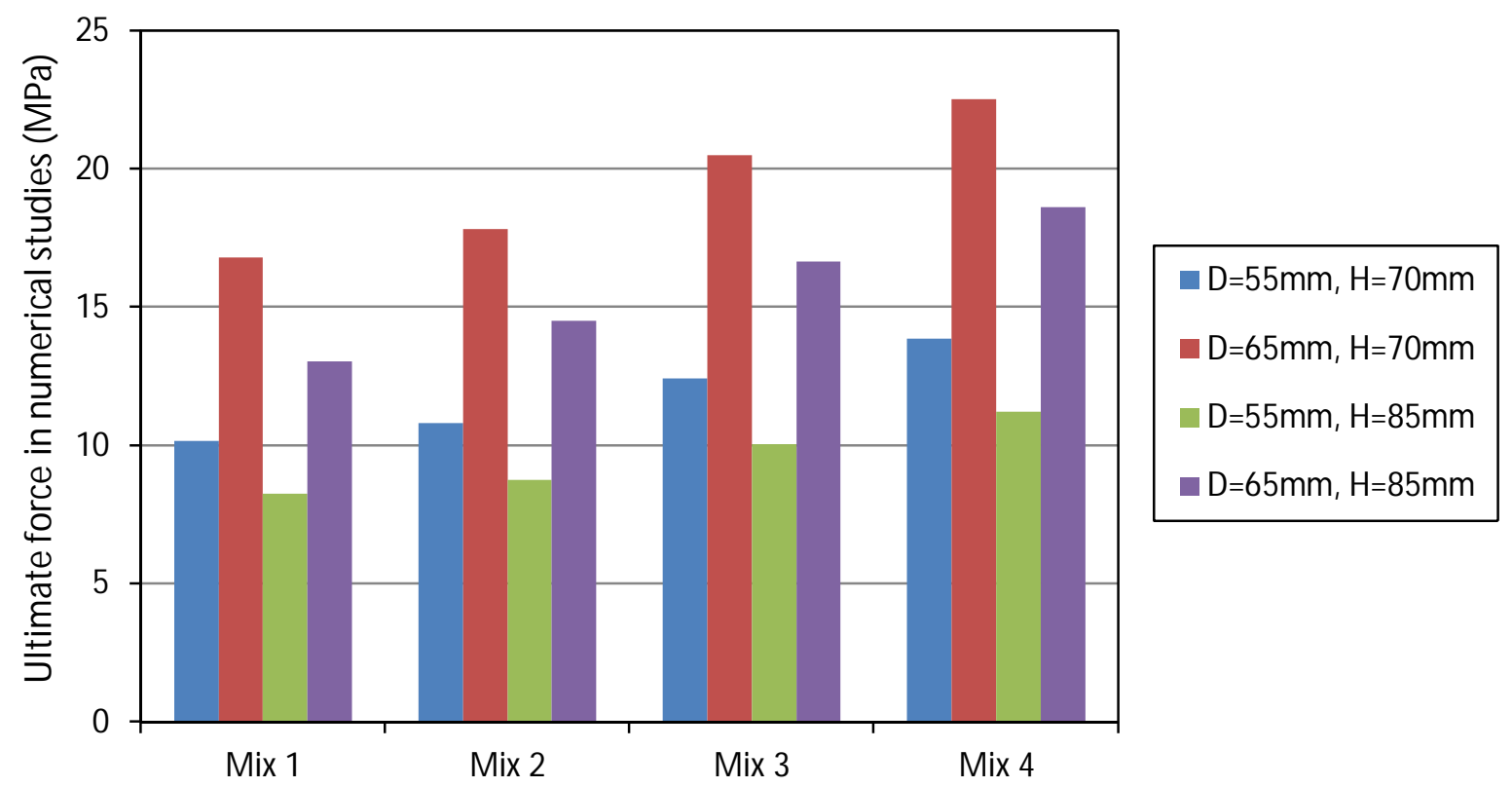

Fig.11. Numerical Results for Different Dimensions of Cylindrical Core in B.O. Test

Fig. 12 shows the contour of maximum principal stress of the model.These contours show that these stresses are more at the base of the B.O. core specimen, where the fracture process occurs.Also, thehighest stresses are concentrated in vicinity of the fracture zone.As shown in Fig. 12, if both diameter and height increase approximately by 20 percent, there is no significant change in the results. But if only diameter or height increases the same percentage, there is a little increase in maximum principal stress by roughly 4 percent was detected. 


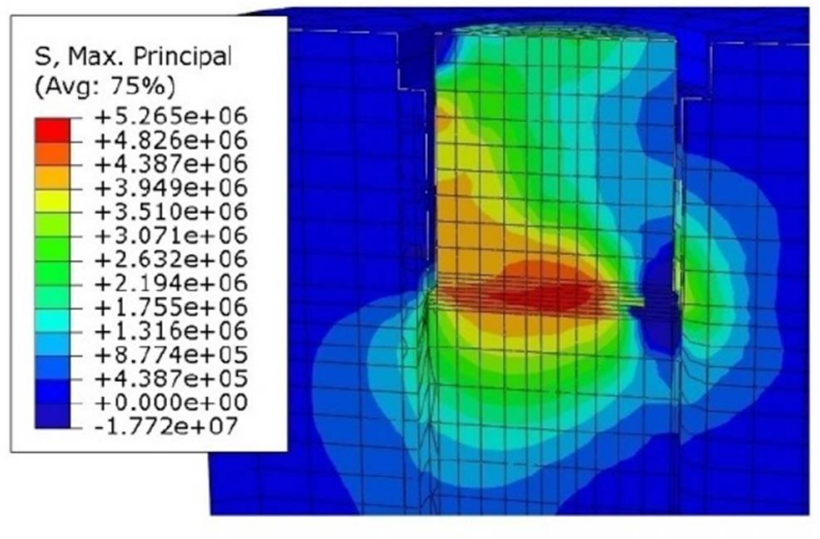

( $\mathrm{D}=65 \mathrm{~mm}, \mathrm{H}=70 \mathrm{~mm}$ )

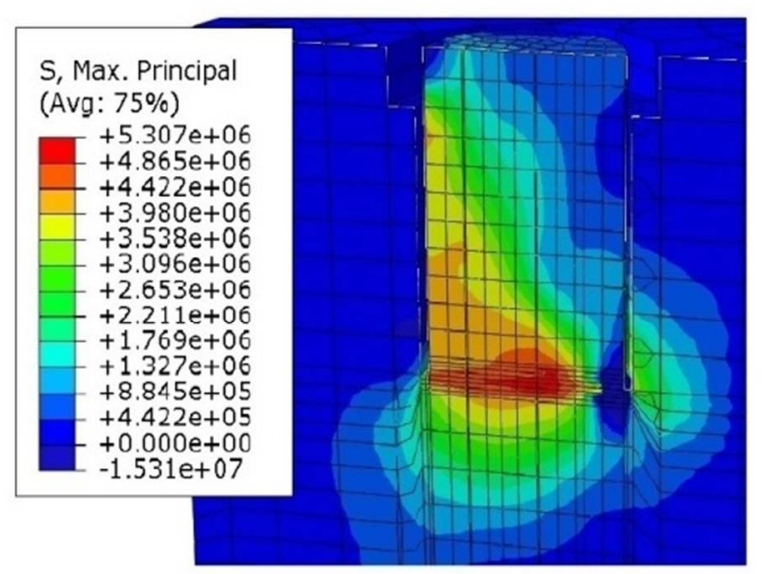

( $\mathrm{D}=55 \mathrm{~mm}, \mathrm{H}=85 \mathrm{~mm}$ )

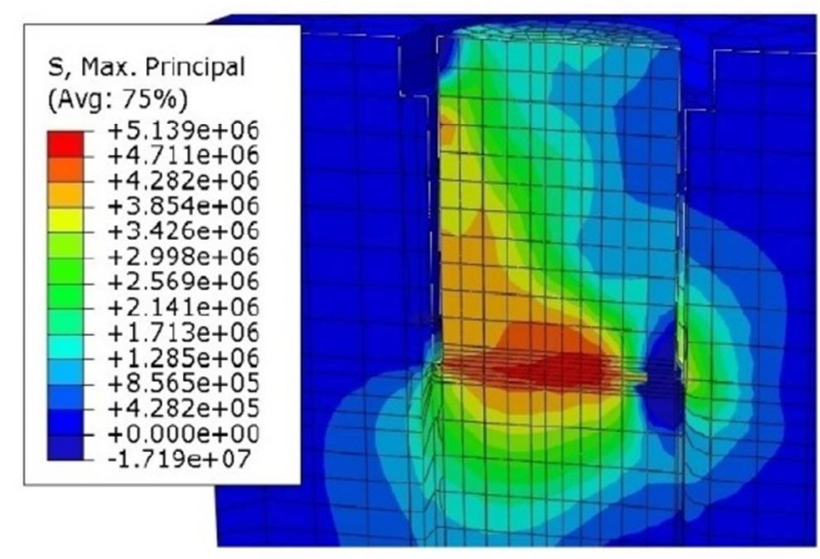

( $\mathrm{D}=65 \mathrm{~mm}, \mathrm{H}=85 \mathrm{~mm}$ )

Fig.12. The distribution of maximum principal stress in parametric studies 


\section{A comparison ofFE modeling ofB.O. test method withmodulus of rupture}

According to studies done by Naik[2, 6],it seems that the B.O. test method can assessthe flexural strength of concrete and the ultimate flexural strength of the concrete is occurred at the base of the B.O. test specimen. Furthermore, in a study reported by Johansen [1], it has been shown that the B.O. test results are, on average, about 30 percent higher than those of modulus of rupture test. The observations of Johansen showed that geometric parameters caused the difference between these two test methods.For further investigation, the numerical results of B.O. test method is compared with modulus of rupture test.

According totheoretical considerations [10], the B.O. stress $\left(f_{B O}\right)$ was defined using Eq. 3.

$$
f_{B O}=\frac{M}{S}=\frac{\mathrm{P}_{\mathrm{BO}} \cdot h}{d / 32}
$$

Where $P_{B O}$ is the concentrated force applied at the top of the B.O. core specimen, $h$ is core depth, and $d$ has been considered thecore diameter as used by Johansen.

At the failure surface of the B.O. method, surrounding area of the base of thecore specimen participates in carrying some of the bearing B.O. force applied in concrete specimen.Consequently, the ultimate force on the B.O. core specimen will be increased.Concerningthe stress distributions at the base of the B.O. core, it seems,the assumption of the effective cross section based on core diameter considered by Johansen in Eq. 3is not realistic. Therefore, by considering the surrounding area of the base of core specimen,the B.O. test resultswouldbe expectedtobe close to the modulus of rupture test. 


\section{Conclusion}

In this paper, the B.O. test was analyzed by means of FE method using ABAQUS software and also parametricstudies were prepared. Furthermore, a comparison of FE modeling of B.O. test method with modulus of rupture has been carried out. The following conclusions can be drawn from thisinvestigation:

- The results demonstrate thatthe developed FE model can give a close prediction of ultimate force in B.O. test method.The average ratio ofultimate force obtained by FE to experimental results wasdetermined to be1.1.

- The fracture zones predicted by the contours of damage were found to be similar to thoseexperimental observations.

- To avoid the interference between the stresses ofneighboring concrete cores, the minimum center to center distance is required to be $120 \mathrm{~mm}$.

- By merely increasing core diameter by about $20 \%$, the ultimate force will increase up to $65 \%$. However,increasingin height by the same percentage will give reverse result and causes adecrease in ultimate force by 19 percent.

- KeepingH/D=1.3, increasing both height and diameter of core by around $20 \%$ willcreate an increase in ultimate force by $34 \%$.

- For different core dimensions, although the values of stresses are not equal, similar stress distributions were detected on the failure surface.

- Although thehighest stresses for B.O. test are concentratedonthe base of core specimen, some energy is absorbed by surrounding area of the base which participates on increasing the ultimate force. 


\section{References:}

[1] Johansen, R. In-situ strengthevaluation of concretethe break-off method. American Concrete Institute, 1(9) (1979) 45-51.

[2] Naik, T.R. Handbook on nondestructive testing of concrete. Chapter 4. The Break-off Test Method, CRC Press, New York, 2004.

[3] Byfors, J. Plain concrete at early ages. Swedish Cement and Concrete Research Institute, Rep. No. Facks-10044, Stockholm. 1980.

[4] Nishikawa, A. A nondestructive testing procedure for in-place evaluation of flexural strength of concrete. Report. No. JHRP 83-10, Joint Highway Research Project, School of Civil Engineering, Purdue University, West Lafayette, Indiana. 1983.

[5] Carlsson, M., Eeg, I., Jahren, P. Field experience in the use of break-off tester. Special Publication, SP 82-14, American Concrete Institute. 82 (1984) 277-292.

[6] Naik, T.R., Salameh, Z., and Hassaballah, A. Evaluation of in-place strength of concrete by the break-off Method, Department of Civil Engineering and Mechanics, 1988.

[7] B.S. 1881. Break-off Test, British Standard, Part 201, 1986, 17.

[8] Nordtest Method NTBUILD 212. Break-off Test, Edition 2, Norway, 1984.

[9] SS 1372319. Break-off Test, Swedish Standard, Sweden, 1983.

[10] ASTM C1150. Standard Test Method for the Break-off Number of Concrete. Annual Book of ASTM Standards,American Standards for Testing and Materials, West Conshohocken; Pa, USA, 1997. 
[11] ASTM C1150, Standard Test Method for the Break-Off Number of Concrete, Annual Bookof ASTM Standards, American Standards for Testing and Materials, West Conshohocken; Pa, USA, 2002.

[12] ASTM C78. Standard Test Method for Flexural Strength of Concrete. American Standards for Testing and Materials, West Conshohocken, Pa, USA, 2009.

[13] Lin Y., Lin Y.F and Hsiao Ch. Evaluation of bond quality at the interface between steel bar and concrete using the small-dimension break-off test. Materials and Structures, 43(5) (2010) 583595.

[14] Abaqus Standard User's Manual, Version (6.11-3), Hibbitt, D., Karlsson, B. and Sorensen, P., 2011.

[15] Barth, K.E. and Wu, H.Y. Efficient nonlinear finite element modeling of slab on steel stringer bridges. Finite Elem. Anal. Des. 42 (2006) 1304-1313.

[16] Lee, J. and Fenves, G.L. Plastic-damage model for cyclic loading of concrete structures. Journal of Engineering Mechanics, 124 (8) (1998) 892-900.

[17] Huu, T.N. and Kim, S.E. Finite element modeling of push-out tests for large studshear connectors. Journal of Constructional Steel Research, 65(10-11) (2009) 1909-1920.

[18] Lubliner J, Oliver J, Oller S, On ate E. A plastic-damage model for concrete. International Journal ofSolids and Structures, 25(3) (1989) 299-326.

[19] Hognestad, E. A study on combined bending and axial load in reinforced concrete members. Univ. of Illinois at Urbana-Champaign, IL, Bulletin Series No. 399, (1951) 43-46. 